\title{
El fin del gobierno alfonsinista y el posicionamiento de un sector de pequeños empresarios
}

\author{
María Alejandra Martínez Fernández \\ (ISHIR-CONICET/UNR)
}

\begin{abstract}
Resumen:
En este trabajo nos centraremos en el posicionamiento que ha tenido un sector de pequeños empresarios agremiados en APYME respecto de los planes aplicados por el último período del gobierno radical del retorno a la democracia. Trataremos las principales medidas que contenían el Plan Austral y el Primavera y la dinámica política que de éstos se emanaba para presentar el diagnóstico que la organización de pequeños empresarios sostenía respecto de los mismos. Finalizaremos el trabajo con la difícil situación económico-social que define la entrega anticipada al gobierno de Carlos Menem.
\end{abstract}

Palabras clave: APYME, Alfonsín, Plan Austral, Plan Primavera.

Abstract: In this paper we are going to concentrate on the position adopted to the implementation of the Plan Primavera, of the UCR's government of the return to democracy, by a sector of small business owners grouped in what is called APYME. In order to understand this subject, we will characterize the "Plan Austral" (1985) proposed by the Minister of Economic Affairs of the UCR's government. We will then point to the most important regulations that the "Plan Primavera" contained, to finally explain how APYME had positioned in front of this plan. We will finish analyzing the complicated situation of the Argentine life, which provoked the end of the UCR's government and cause this to pass the power to new elected government whose president was Carlos Menem before the stipulated date. Key words: APYME, Alfonsín, Plan Austral, Plan Primavera.

Nos referiremos en este trabajo al posicionamiento que un sector de pequeños empresarios ha tenido en los años finales del gobierno alfonsinista. Cuando se trabaja este período es frecuente encontrar análisis respecto de otras organizaciones empresarias ${ }^{1}$ que por su

1 Para profundizar acerca del posicionamiento de organizaciones empresarias más tradicionales se pueden consultar entre otros ACUÑA, Carlos, La burguesía como actor político, tesis de doctorado, Universidad de Chicago, 1995; BASUALDO, Eduardo, KHAVISSE Miguel y AZPIAZU Daniel, El

MARTÍNEZ FERNÁNDEZ, María Alejandra "El fin del gobierno alfonsinista y el posicionamiento de un sector de pequeños empresarios", en Avances del Cesor, Año IX, $\mathrm{N}^{\circ}$ 9, 2012, pp. 55-72. 
poder económico y político han tenido una mayor centralidad, sin embargo consideramos que enriquecería la comprensión el indagar acerca del comportamiento de una organización que recién se conformaba y que representa un sector nada despreciable como el de los pequeños empresarios. Nos estamos refiriendo a la Asamblea de Pequeños y Medianos Empresarios (APYME).

Este trabajo es parte de una investigación más amplia en la que nos centramos en APYME Rosario (1987-2011), la cual se encuentra en estado inicial y se utilizan técnicas de investigación clásicas de la antropología como las entrevistas en profundidad, observación de diferentes actividades, aunque esos registros no son utilizados en este escrito. Además del relevamiento de un cuerpo de fuentes, sobre las que está construido este trabajo, específicamente los documentos de la organización producidos entre 1987 y 1989 y noticias en distintos periódicos que hacían referencia a la misma. Intentamos a través de estas fuentes realizar una aproximación antropológica que rescate los sentidos y el diagnóstico que los propios actores hacían para dar cuenta de su posicionamiento.

\section{La Asamblea de Pequeños y Medianos Empresarios}

La Asamblea de Pequeños y Medianos Empresarios nace ${ }^{2}$ formalmente el 15 de mayo de 1987 gestada en el interior del movimiento cooperativo de crédito por dirigentes que participaban del Instituto Movilizador de Fondos Cooperativos (IMFC). La intención era cubrir un 'vacío de representación' que a su entender dejaban el resto de las entidades empresariales las cuales, lejos de representar a los pequeños empresarios, tergiversaban las preocupaciones y las demandas de éstos. Algunos de estos empresarios también habían participado de la CGE, pero evaluaban que debían dar origen a una nueva organización puesto que "muchos dirigentes y entidades que representaban al empresariado nacional y a las pequeñas y medianas empresas (pymes), que jugaron un papel importante en la lucha contra la dictadura y por la restauración de la democracia, fueron adecuando su prédica en aras del 'posibilismo'. De hecho se fueron colocando del lado de las organizaciones tradi-

nuevo poder económico en la Argentina de los 80, Hyspamérica, Buenos Aires, 1986; BELTRÁN, Gastón, La acción empresarial en el contexto de las reformas estructurales de las décadas de los ochenta y los noventa en Argentina, tesis de doctorado, Facultad de Ciencias Sociales UBA, 2007; LATTUADA, Mario, Acción colectiva y corporaciones agrarias, Universidad Nacional de Quilmes, Buenos Aires, 2006. OSTIGUY, Pierre, Los capitanes de la industria, Editorial Legasa, Buenos Aires, 1990.

2 No ahondaremos demasiado en el momento del surgimiento debido a que el objetivo es mostrar el posicionamiento que han tenido respecto de los planes aplicados en el período considerado. Para profundizar sobre el particular se pueden consultar de la misma autora Analizando el surgimiento de un nuevo APYME actor político: APYME, Revista de la Escuela de Antropología, Volumen XVII, 2011. 
cionales que representaban al statuo quo y respondían a las concepciones libreempresistas y liberales". ${ }^{3}$

El encuentro con el que nace formalmente la organización fue realizado en la Unión Industrial de Avellaneda el 15 de mayo de 1987 y concurren dirigentes de Capital Federal, Buenos Aires, Santa Fe, Córdoba, Mendoza, Entre Ríos y Jujuy. Allí se sentaron las bases de la futura organización y se hizo pública su Declaración de Principios en la que se establecía como objetivo "nuclear a los pequeños y medianos empresarios industriales, comerciantes, prestatarios de servicios y productores agrarios con el objeto de promover la defensa de los intereses comunes en el marco de la consolidación de la democracia y el logro de la independencia económica". ${ }^{4}$

Esta organización no funciona como una cámara en la que se asocia la empresa según la actividad, sino que se asocian los empresarios que pertenecen tanto al sector industrial como al de comercio o servicios.

El planteo central de la propuesta elaborada en el "plenario fundacional" de 1987, que consideramos constituye una de las características más importantes de la organización, es el papel adjudicado al mercado interno, a los trabajadores, jubilados y pequeños empresarios como parte sustancial del mismo. El crecimiento sólo puede lograrse atendiendo a estos sectores: "la reactivación y el desarrollo económico deben tener como eje fundamental la ampliación del mercado interno, para lo cual se requiere recuperar el poder adquisitivo de amplios sectores de la sociedad". ${ }^{5}$

Se expresaba en este documento además la necesidad de reestructurar el sistema impositivo, disminuyendo el peso de la tributación al consumo; una política salarial armónica y equitativa que incremente la capacidad adquisitiva de la población; control sobre el comercio exterior y sobre los precios focalizando en las empresas formadoras de precios; según hemos planteado, para esta organización era prioritario el fomento del mercado interno para lograr el desarrollo y el bienestar de quienes lo componen.

APYME reconocía que los cambios operados en la dictadura habían modificado sustancialmente la estructura productiva y había beneficiado a ciertos grupos económicos, nacionales y extranjeros, que tenían capacidad de apropiarse de las transferencias que el Estado realizara y para fijar sus precios de modo tal de incidir en el resto de los actores.

Evaluaban que la estrategia del radicalismo no atendía al objetivo de recuperación del mercado interno sino que por el contrario los planes aplicados desde 1985 transferían recursos a los grupos concentrados y de este modo lo restringían; afectando negativamente a pymes y asalariados, tal como podemos observar en un discurso de uno de sus dirigentes "sólo han servido a los intereses de la banca internacional y a determinados grupos concentrados

3 APYME, Documento 10 años de APYME, Buenos Aires, mayo de 1997.

4 APYME, Declaración de Principios, Avellaneda, mayo de 1997.

5 APYME, Propuesta para la reactivación y el desarrollo económico, Avellaneda, mayo de 1997. 
del país, los beneficiados de estas políticas son los mismos grupos concentrados foráneos y locales que desde la época del proceso nos sumieron en la mayor dependencia". ${ }^{6}$ Considerando que el sector de pequeños empresarios al que representan se veía particularmente afectado: "la situación del pequeño y mediano empresario se desenvuelve en los límites de la subsistencia".?

Para poder entender en qué se basaba la organización para realizar estas afirmaciones, presentaremos los lineamientos fundamentales del Plan Austral.

\section{El Plan Austral: el déficit fiscal y la inflación, nuevas prioridades}

El gobierno radical de 1983 conducido por Raúl Alfonsín inaugura el retorno a la democracia, es la primera vez que el radicalismo es electo para gobernar el país sin la proscripción del peronismo. Con un discurso que enaltecía las virtudes de la democracia, el candidato radical logró el $51,9 \%$ de los votos, venciendo al justicialismo que obtuvo el $40,2 \% .{ }^{8}$ La política económica quedó a cargo de Grinspun al comienzo de la presidencia de Alfonsín, su estrategia era lograr la reactivación del mercado interno con una política de redistribución del ingreso, mediante la recuperación del nivel de salarios, expansión del PBI y la negociación de la deuda a través de un club de deudores.

El recambio de Grinspun por Sourrouille en 1985 y el Plan Austral puesto en marcha por este nuevo equipo económico, marca el inicio de una nueva etapa. El principal problema a resolver era la inflación que se consideraba ahora causada por el desequilibrio de las finanzas públicas, desde entonces déficit fiscal y deuda externa se constituían en el eje de las preocupaciones.

Dada la centralidad que adquirían en esta formulación el ordenamiento de las cuentas públicas y la restructuración del Estado, los organismos financieros internacionales brindaron su apoyo a las medidas y el programa fue directamente discutido en esos ámbitos, convirtiéndose en actores centrales de la política en Argentina. Canitrot, quien fuera Secretario de Coordinación Económica del equipo conducido por Sourrouille, manifestaba que "el acuerdo no representó sino la aceptación de dependencia en el plano económico con los EEUU [que] han ejercido a partir de 1985 un control indirecto de la gestión económica argentina a través de los préstamos del FMI y el Banco Mundial. El gobierno argentino...

6 APYME, Publicación de APYME Rosario, Año 2, №9. Rosario, Julio de 1993.

7 APYME, Propuesta para la reactivación y el desarrollo económico, Avellaneda, mayo de 1997.

8 Para profundizar sobre el particular se pueden consultar: VOMMARO, Gabriel, "Cuando el pasado es superado por el presente: las elecciones presidenciales de 1983 y la construcción de un nuevo tiempo político" y PESCE, Julieta, "Política y economía durante el primer año del gobierno de Alfonsín", en PUCCIARELLI, Alfredo (coordinador) Los años de Alfonsín, Siglo XXI, Buenos Aires, 2006. 
debe pagar los costos de cualquier resistencia por las reacciones negativas que ésta produce en los operadores financieros del propio país. Estas reacciones no son siempre menores, como se demostró en febrero de 1989". ' Sourrouille sostuvo que el Plan Austral se negoció en los EEUU ante los representantes Fondo Monetario Internacional y de la Reserva Federal, en una reunión a la que concurrieron Mario Brodersohn (Secretario de Hacienda), José Luis Machinea (Banco Central) y él mismo. Reconociendo la sorpresa que le provocó al ministro que "un gobierno conservador" de EEUU y el Fondo aprobaran un plan que incluía congelamiento de precios, expresó: "allí fuimos Mario, José Luis y yo a exponer el Plan Austral al Fondo, y ahí estaba la crema del mundo... el 28 de abril quedó hecho el austral... si con alguien habíamos conversado sobre el plan fue con el gobierno de EEUU, que no sólo lo había apoyado sino que puso mucho dinero detrás de esa operación". ${ }^{10}$

Aparecía ya nítidamente la referencia a las "reformas estructurales" como la única solución posible aplicadas en profundidad un tiempo después, que no eran únicamente defendidas por los organismos internacionales sino que también respondían a una presión interna de grupos concentrados locales y extranjeros para que las mismas se concreten.

El Plan Austral, lanzado el 14 de junio de 1985 con el objetivo de contener la inflación, cambiaba el signo monetario adoptando el Austral como denominación (que equivalía a 1.000 pesos argentinos y a 80 centavos de dólar) y congelaba las principales variables de la economía (tipo de cambio, salarios, precios industriales, tarifas de servicios). El gobierno se comprometía a no emitir moneda para financiar el déficit, además de buscar financiamiento en el exterior y aumentar las retenciones a las exportaciones.

Si bien se congelaban los precios a partir del lanzamiento del plan, en los meses previos se registraron aumentos en algunos precios industriales y en las tarifas de servicios. Tal como lo plantean Schorr y Ortiz "entre abril y junio [de 1985] se hicieron más flexibles los controles de los precios industriales, eliminándose en muchos casos los mismos y permitiendo la formación de un 'colchón [de precios]".."11

El plan mostró resultados esperanzadores en la primera etapa ya que la inflación (si bien creció y nunca se detuvo) pudo contenerse en parte: "en el año más exitoso en esta materia 1986 , los precios minoristas crecieron 'apenas' un $81 \%$ y los mayoristas un 58\%" ${ }^{12}$ Schorr

9 CANITROT, Adolfo, "La macroeconomía de la inestabilidad. Argentina en los 80", en Boletín Informativo Techint, $N^{\circ} 272$, Buenos Aires, 1992. Disponible en:

http://www.boletintechint.com/boin/OpenFile.asp?file=pdf \AR428.pdf

10 Entrevista a Juan Sourrouille, Red de Archivos de Historia Oral, Instituto Gino Germani, UBA, Buenos Aires, 28/9/2005.

11 ORTIZ, Ricardo y SCHORR, Martín, "La economía política del gobierno de Alfonsín", en PUCCIARELLI, Alfredo (coordinador), Los años de Alfonsín. ¿El poder de la democracia o la democracia del poder?, Siglo XXI, Buenos Aires, 2006.

12 Ibídem. 
y Ortiz adjudican el crecimiento de la inflación, entre otros factores, a la gran concentración resultante de las políticas de la dictadura que consolidó ciertos grupos económicos con gran poder de mercado y con capacidad para determinar sus precios e incidir en los precios relativos del conjunto de la economía local. Veremos más adelante cómo APYME hace alusión constante a los formadores de precios como los responsables de la inflación.

En una entrevista el ex presidente Alfonsín aludía a los objetivos del plan "yo pensé que podía limitarse la inflación, no controlarla absolutamente pero si limitarse. Pienso que ese era uno de los objetivos del Plan Austral. Pero inmediatamente la CGT empezó a trabajar para hacerlo fracasar y salió reclamando aumentos de salarios que desde luego provocaban una inflación mayor. Sin política de contención de precios, aunque las tenía el Plan Austral pero era más difícil de llevarlas adelante, los precios suben cuando hay aumento de salarios. Y como decía Perón, los salarios suben por la escalera y los precios por el ascensor”. En cuanto al funcionamiento del plan el ex presidente consideraba que "el Plan Austral funcionó muy bien, pero tal vez no se pudo contener algún gasto también. Porque el plan necesitaba contención del gasto público y un fisco que se bastara a sí mismo, que evitara la inflación que lleva la emisión de billetes. No se pudo contener del todo, todo eso. Pero fundamentalmente fue la política de la CGT la que nos fue llevando a una situación que prácticamente lo esterilizó al Plan Austral". ${ }^{13}$ Abonaba así al argumento de que era la puja distributiva ${ }^{14}$ y el tipo de Estado obsoleto lo que ocasionaba la inflación, subestimando las transformaciones en la estructura productiva encaradas en la última dictadura militar.

\section{El Austral empieza a mostrar sus debilidades:}

A pesar del éxito inicial, los problemas comenzaron a hacerse evidentes y al flexibilizarse los controles se empezaron a registrar sostenidos aumentos de precios, el año 1988 se presentaba con una inflación que crecía a ritmos notables. Entre septiembre de 1987 y agosto de 1988 los precios minoristas se habían incrementado un $440 \%$, mientras que los mayoristas lo hicieron en $606,5 \% .{ }^{15}$

APYME aparece en la arena política en el transcurso en que el plan austral estaba

13 Entrevista a Raúl Ricardo Alfonsín, Red de Archivos de Historia Oral, Instituto Gino Germani, UBA, Buenos Aires, Agosto-setiembre de 2005.

14 Respecto de los conflictos con la CGT y entre distintas fracciones de clase, se pueden consultar: ARUGUETE, Eugenia "Lucha política y conflicto de clases en la posdictadura. Límites a la constitución de alianzas políticas" y PESCE, Julieta, "Política y economía durante”..., Op. Cit.; y ACUÑA, Carlos, La burguesía como actor político, Tesis de Doctorado, 1995 y ACUÑA, Carlos y GOLBERT, Laura, "Empresarios y política. Parte II. Los empresarios y sus organizaciones ¿Qué pasó con el Plan Austral?", en Boletín Informativo Techint No 263, 1990. Disponible en: http://www.boletintechint. com/boin/OpenFile.asp?file=pdf \AR611.pdf

15 ACUÑA, Carlos, La burguesía industrial..., Op. Cit. 
siendo aplicado, manifestándose en contra de la estrategia del radicalismo ya que según su concepción "la crisis por la que atraviesa la pequeña y mediana empresa no encuentra respuesta en el marco de la actual política económica. Ésta privilegia el mercado externo y se orienta a cumplimentar los intereses de la banca extranjera y del FMI. La deuda externa empobrece al país y lo sume en la dependencia". ${ }^{16}$

Esta organización reconocía como un grave problema la pérdida de soberanía que implicaba tener que negociar los planes económicos con el gobierno de EEUU y los organismos internacionales de crédito, porque la deuda externa actuaba como un serio condicionante para el país: "durante estos últimos 4 años se [otorgó] prioridad al pago de los intereses de la deuda externa por sobre la asignación de recursos destinados a la producción y a la inversión... Sabemos que la deuda externa no es la única causa de la afligente situación de países como el nuestro, pero sí la principal restricción". ${ }^{17}$

APYME consideraba que la inflación se debía, no a variables económicas fuera de control, sino que existían responsables políticos de esta situación. Se trataba de los grupos concentrados que desde la dictadura militar de 1976 se habían consolidado como un nuevo bloque de $\operatorname{poder}^{18}$ y se habían apropiado de cuantiosas transferencias estatales. Es por ello que la denuncia a los grupos concentrados como los responsables se reitera en muchas oportunidades. En el plenario realizado en noviembre de 1987 encontramos declaraciones en este sentido, "preocupa el tratamiento al pequeño y mediano empresario al que se quiere hacer aparecer como culpable del encarecimiento y distorsiones del mercado, cuando todos saben quiénes fijan los precios. Son las empresas líderes que monopolizan el mercado". ${ }^{19}$

En una entrevista que le hicieran al presidente de la delegación Rosario, éste declaraba que "sin recuperar el mercado interno mediante la recomposición del poder adquisitivo de la población, no existen posibilidades reales de un desarrollo armónico de nuestra economía... Debe ejercerse una política de control de precios focalizada en las empresas formadoras de precios y exigir correctivos al gobierno de esta política de achicamiento del mercado interno que muestra continuidad con Martínez de Hoz". ${ }^{20}$

Algunos preceptos ideológicos de los miembros de la organización se hacen visibles en los diagnósticos que ésta sostiene, entre ellos el fortalecimiento del mercado interno a través de una alianza política entre trabajadores y pequeños empresarios como parte sustancial de los sectores populares que reivindique un programa de "contenido nacional", para

16 APYME, Propuesta para la reactivación y el desarrollo económico, Avellaneda, 15/5/1987.

17 APYME, Las pymes enfrentan la crisis nacional, Buenos Aires, junio 1988.

18 BASUALDO Eduardo, KHAVISSE Miguel y AZPIAZU Daniel, El nuevo poder..., Op. Cit., p. 10.

19 APYME, Documento Plenario Nacional, Avellaneda, 20/11/1987

20 Diario La Capital, Rosario, 9/3/1988. 
hacer frente al bloque de poder que se había consolidado en Argentina desde la dictadura modificando cualitativamente la estructura socioeconómica del país.

Una solicitada publicada por APYME mostraba la preocupación por la acentuación de la crisis a comienzos de 1988, en la que se establecía que "después del salario, las pymes pasan a ser la más importante variable de ajuste que deriva en una mayor depresión de la actividad económica y el mercado interno... De este modo el equipo económico logra recursos para transferirlos hacia los grupos económicos concentrados, la oligarquía financiera, para el pago de la deuda externa y compromisos con el FMI. Cada acuerdo de Machinea, Brodersohn y Sourrouille con el FMI es ajuste sobre ajuste... ¿ ¿Si se restringe aún más el mercado interno y la tasa de interés está por sobre la rentabilidad media, quién va a invertir para lograr crecimiento y desarrollo?". ${ }^{21}$

Un mes más tarde, la organización volvía a manifestar a través de otra solicitada "las empresas líderes están prostituyendo la comercialización utilizando la sobrefacturación y el desabastecimiento. Son las mismas que se benefician con la política oficial. Hechos que confirman lo que APYME viene sosteniendo: sin terminar con el Plan Austral, sin revertir globalmente la política económica, no habrá soluciones". ${ }^{22}$

Es por ello que exigían una sustancial transformación de la política económica que "honrara las deudas con la población y no con los organismos". Por junio de 1988 APYME elabora un documento titulado "Las pymes enfrentan la crisis nacional", en el que establecen que "la magnitud de la crisis que agobia a sectores mayoritarios de la sociedad argentina no entrará en vías de solución sin que se produzca un viraje profundo en el rumbo de la conducción económica". Para atender las presiones de la banca acreedora y de los organismos internacionales que actuaban como agente político, manifestaba APYME que el gobierno radical elaboró "metas en función de incrementar el saldo favorable de la balanza comercial... también debió recurrir a un costosísimo endeudamiento interno a través de la emisión de títulos públicos con rentas exorbitantes", mientras tanto "el mercado interno se deprime cada vez más y como para las pymes se trata de su fundamento, la crisis del sector se profundiza". ${ }^{23}$

Con la situación política agudizada, se habían producido algunos levantamientos militares y el radicalismo había perdido las elecciones parlamentarias de septiembre de 1987, el gobierno esperaba a través del llamado Plan Primavera de 1988 controlar las principales variables económicas para que el candidato radical, Angeloz, tuviera alguna chance en las presidenciales de 1989. Según lo expone Sourrouille el plan se implementó con "la idea

21 Diario La Ciudad de Avellaneda, Avellaneda, 18/2/1988. Archivo APYME Buenos Aires.

22 Diario El Pregón, Avellaneda, 4/3/1988. Archivo APYME Buenos Aires.

23 APYME, Las pymes enfrentan..., Op. Cit. 
de poder preparar una situación de convivencia razonable para la elección presidencial del año siguiente". ${ }^{24}$

En el apartado siguiente nos detendremos en las principales disposiciones que el Plan Primavera contenía.

\section{Ajuste para el Austral: se intenta con el Primavera}

Era lunes $1^{\circ}$ de agosto de 1988, el país amanecía con la noticia que el gobierno había dispuesto feriado bancario y cambiario por dos días con la finalidad de preparar el terreno para el anuncio de un nuevo plan antiinflacionario como un intento de reencauzar el Plan Austral de 1985 que se mostraba incapaz de cumplir con los objetivos propuestos.

$\mathrm{El}$ anuncio del feriado fue realizado por el vocero presidencial que descartó un congelamiento de precios y expuso que se haría un acuerdo con empresarios para fijar pautas que ayuden a contener la escalada inflacionaria- ${ }^{25}$ Circulaban varias versiones acerca del contenido de las medidas y de que el Ministro de Agricultura renunciaría. ${ }^{26}$ Según publicaba Clarín "se barajaron distintas fechas, pero las filtraciones que amenazaban quitarle al plan todo su efecto sorpresa y la aceleración inflacionaria generada por las expectativas, obligaron a adelantar la puesta en marcha". ${ }^{27}$

El plan se basaba en un acuerdo con la cúpula de la Unión Industrial Argentina (UIA) y la Cámara Argentina de Comercio (CAC) y con el gobierno de EEUU que, a través del FMI y del Banco Mundial, se comprometía a desembolsar créditos para el país.

Según el presidente Alfonsín el plan para ser exitoso debía tener el apoyo de los empresarios más poderosos y por ello buscaron negociar con la UIA "sí hubo [negociación] cuando pusimos en marcha el Plan Primavera que era un plan mucho más débil, era necesario tener relaciones con los empresarios a efectos de contener los precios... llegamos a algunos

24 Entrevista a Juan Sourrouille, Red de Archivos de Historia Oral, Instituto Gino Germani, UBA, Buenos Aires, 5/10/2005.

25 Diario La Capital, Rosario, 1/8/1988.

26 El Ministro de Agricultura, Ernesto Figueras, estaba vinculado a la Sociedad Rural y había amenazado con renunciar 'si el plan afectaba nuevamente los intereses del sector agropecuario' (ver ACUÑA, Carlos y GOLBERT, Laura, "Empresarios y política...”, Op. Cit. y ACUÑA, Carlos, La burguesía como..., Op. Cit.) Algunas de las versiones que circulaban en los medios en aquellos momentos refieren a que justamente el acuerdo de precios con las corporaciones se dificultaba y ello imposibilitó anunciar el plan dentro del plazo establecido. A raíz de lo cual, el feriado bancario se extendió y la conferencia de los funcionarios anunciando las medidas se concreta el 3 de agosto, después que se incrementaran un $30 \%$ las tarifas de servicios públicos y los combustibles el día anterior.

27 Diario Clarín, Buenos Aires, 1/8/1988. 
éxitos pero en definitiva se produce también la inflación hasta que tenemos que cambiar el tipo de cambio en febrero y eso desató la hiperinflación". 28

El paquete de medidas pretendía reducir la pauta inflacionaria cercana al 30\% mensual a menos del $10 \%$, incluía un congelamiento de precios y una comisión que se encargaría de supervisarlos. ${ }^{29} \mathrm{El}$ austral fue devaluado un $11,4 \%$, se establece un dólar relativamente bajo como mecanismo de contención de precios internos, y para controlar el precio del dólar el gobierno ofertaba divisas en el mercado.

Se produce un desdoblamiento del mercado cambiario en un dólar comercial (que valía 12 australes) al que se liquidaban las exportaciones del campo; $y$ otro financiero levemente superior para el resto de las operaciones (cuyo valor era 14,40 australes), para lograr apropiarse de una parte de las divisas generadas por los exportadores, "retenciones disimuladas" decían los periódicos, si bien la intención declarada del gobierno era unificar el mercado cambiario para abril de 1989. Se incrementaban en $25 \%$ los salarios del sector público y se llamaban a paritarias para los privados.

Otro de los puntos que incluía el plan era una disminución de la alícuota del IVA del 18 al $15 \%$, lo cual generó alguna controversia en el FMI ${ }^{30}$ tan es así que Brodersohn (Secretario de Hacienda) en la conferencia de prensa en la que lo anunciaran afirmó que si había fallas fiscales sería replanteado el recorte del IVA. También incluía una reducción de las barreras arancelarias y una simplificación para la importación de ciertos productos a los que se eliminaba del régimen de consulta previa. Las anteriores disposiciones iban acompañadas de una racionalización administrativa, recortes a obras públicas y continuaban los infructuosos intentos de privatización de empresas estatales. Todo lo anterior dentro de un marco de elevadas tasas de interés.

Lejos de hacer perder al especulador, como dijera Alfonsín ${ }^{31}$ cuando el plan fue presentado, la especulación trepó a niveles insospechados.

Los grandes grupos económicos aprovecharon estas elevadas tasas de interés que pagaban los depósitos en australes para después comprar dólares. La misma lógica de funcionamiento del plan otorgaba una gran capacidad para condicionar al gobierno a quienes

28 Entrevista a Raúl Ricardo Alfonsín, Red de archivos de historia oral, Instituto Gino Germani, UBA, Buenos Aires, Agosto-setiembre de 2005.

29 Se había establecido un congelamiento de precios hasta el día 15 de agosto, después de esa fecha y hasta fin de mes se autorizaban aumentos por 1,5\%. En setiembre el alza permitida era del 3,5\% y posteriormente una comisión de "seguimiento y control" integrada por empresarios y el gobierno decidiría los pasos a seguir. Diario La Capital, Rosario, 4/8/1988.

30 El organismo internacional lo objetaba porque con esta disminución del IVA (Impuesto al Valor Agregado) se verían afectados los recursos con los que se pagarían los vencimientos de la deuda.

31 El presidente Raúl Ricardo Alfonsín sostuvo que "quien va a pagar más es la especulación, porque cuando la inflación baja desaparece la especulación”. Diario Clarín, Buenos Aires, 4/8/1988. 
poseían las divisas (los exportadores y la banca acreedora). Si decidían no liquidarlas, el dólar se disparaba: "el plan requería un fuerte ingreso de divisas a corto plazo para poder mantener controlada la tasa de cambio. Para ello se fijaron altas tasas de interés, con lo cual se fomentó la entrada de dólares que se pasaban a australes; éstos se colocaban en el circuito financiero, posteriormente se retiraban capital e intereses ganados, se convertían a dólares y se obtenía una ganancia en divisas superior a la que podía lograrse en otras plazas financieras". 32

El circuito se cerraba con la final salida de las divisas lo que generaba al Banco Central la necesidad de obtener nuevos fondos para compensar los que se retiraban y así contener la tasa de cambio. Estos fondos que provenían de préstamos internacionales conllevaban una pérdida de soberanía y múltiples condicionantes para ser desembolsados.

Ante la imposibilidad de llegar a nuevos acuerdos con el FMI debido al incumplimiento en los pagos asumidos (no se pagaban los vencimientos con la banca acreedora desde abril de 1988) fracasa el envío de nuevos fondos y la situación se torna aún más precaria a comienzos de 1989.

El plan no obtuvo una respuesta uniforme de parte de las corporaciones empresarias. ${ }^{33}$ Por un lado la UIA y CAC lo apoyaron y fueron de hecho las que acordaron el control de precios; pero en seguida se escucharon los reclamos de las organizaciones del campo, aduciendo que se trataba de "otra injustificada transferencia" de ingresos desde el sector agroexportador al industrial.

Con un comunicado firmado en conjunto por 4 entidades del campo el día que el plan se dio a conocer, éstas manifestaban que se trataba de medidas "alentadas por quienes procuran apropiarse indebidamente del esfuerzo de los productores mediante mecanismos que recrean las retenciones a la exportación a través de diferenciales cambiarios, dando un duro golpe contra quienes invierten y se preparan para producir y exportar más, conforme requieren las graves circunstancias del país" ${ }^{34}$ Recordamos el abucheo que enfrentó Alfonsín cuando fue a la inauguración de la $102^{\circ}$ Exposición de agricultura y ganadería en la Rural, el 14 de agosto, recién lanzado el Primavera.

La UIA se comenzó a mostrar preocupada por el atraso cambiario y se sumaba a las presiones devaluadoras que sostenían los agroexportadores (que además reclamaban la unificación cambiaria), abonando las críticas cada vez más frecuentes de que existía recesión, atraso cambiario y altas tasas de interés que afectaban negativamente a la producción. De modo que el apoyo brindado por estos industriales al principio del plan se estaba evaporando.

La mecánica del plan significó enormes ganancias para quienes pudieron hacer uso de

32 SCHORR, Martín y ORTIZ, Ricardo "Crisis del Estado y pujas interburguesas", en PUCCIARELLI, Alfredo (coordinador), Los años de Alfonsín ..., Op. Cit., p. 472.

33 Ver nota al pie $\mathrm{N}^{\circ} 2$.

34 Diario Clarín, Buenos Aires, 3/8/1989. 
ese circuito financiero; mientras que para otros significó el deterioro de su posición relativa. Entre estos sectores resultaron afectados particularmente las pymes, retomando lo planteado por Rapoport ${ }^{35}$ "las tasas de interés positivas afectaban en especial a las empresas pequeñas y medianas, con menor acceso al crédito externo o a las franjas preferenciales del mercado interempresario. Esto por supuesto, implicaba una presión recesiva". A continuación vamos a referirnos a cómo se posicionó esta organización de empresarios cuando se implementa el Plan Primavera.

\section{APYME frente al plan Primavera}

Una vez en marcha el Plan Primavera en agosto de 1988, APYME realizó diferentes actividades en la que movilizó a sus asociados para ocupar la calle y manifestarse de forma visible. Podemos observar que desde entonces la organización esgrime una mayor capacidad de acción colectiva contenciosa, durante el primer año se limitaba a declaraciones en contra de la política económica y a organizar sus delegaciones. Esa será más adelante una característica de la organización por la que serán reconocidos en la década siguiente, la realización de acciones colectivas contenciosas a decir de Tilly, ${ }^{36}$ movilizaciones de carácter disruptivo a raíz de las cuales, algunos dirigentes empresarios se referían a ellos como "empresarios piqueteros". ${ }^{37}$

En Rosario, por ejemplo, se llevó a cabo una caravana de protesta. Según sus dirigentes expresaron al diario local la idea era "romper con la tradicional protesta de empresarios que siempre se han manifestado sólo con paros y cierres. Porque somos parte del pueblo y quienes más en contacto estamos con la realidad económica, es que hacemos este reclamo". 38 Los volantes repartidos en esa ocasión decían "basta de reducción al consumo, de impuestazos y tarifazos, de cierres de empresas y de sumisión a los acreedores externos. ¡Resista la dictadura económica!".

Frente al Congreso Nacional se realizó un bocinazo de protesta, declaraban en aquella oportunidad que "el paquete antiinflacionario conduce a una mayor recesión que reducirá

35 RAPOPORT, Mario, Historia económica, política y social de la Argentina (1880-2003), Emecé, Buenos Aires, 2010.

36 TILLY, Charles, “Acción colectiva”, en Apuntes de Investigación del CECyP, №6, Año IV, Buenos Aires, 2000.

37 Ver MARTINEZ FERNANDEZ María Alejandra, No todos fuimos neoliberales. El caso de pequeños empresarios agremiados en APYME, 2012 (mimeo). Se trata de otro trabajo nuestro en el que analizamos estas cuestiones las cuales, por razones de pertinencia, no podemos profundizar aquí.

38 Diario La Capital, Rosario, 12/8/1988.

66 
aún más el mercado interno. Los ingresos de las pymes, trabajadores y pasivos serán otra vez variable de ajuste". ${ }^{39}$

Unos meses después de declarado el plan primavera, el 5 de octubre, convocan desde APYME a un acto que reunía a dirigentes de todo el país en el Teatro Astral en Buenos Aires, con la consigna "Reactivación del mercado interno. Democracia con contenido nacional y social". La declaración de aquél acto manifestaba que "a la incertidumbre de los tarifazos, al agobio de los impuestos inequitativos e injustos, a las altas tasas de interés, al aumento desmedido de las empresas líderes, sigue ahora una recesión manifiesta como parte del Plan Primavera, que tras una aparente estabilidad no alcanza a ocultar la inflación latente... Son en definitiva los grandes grupos económicos concentrados, los capitanes de la industria, la oligarquía agroexportadora, las transnacionales y la gran banca especulativa y usuraria, los que se benefician e imponen esta política". Afirmaban además, que al no atacar las verdaderas causas que posibilitan la inflación, ésta "rebrotará".

Podemos observar que "APYME entiende que la solución de fondo pasa por el cambio total de la política económica del gobierno y de los grupos concentrados y el FMI. Sólo una mayor incidencia de la gran mayoría del pueblo sobre el Estado podrá sustituir estos planes económicos por otro de contenido nacional y que contemple la reactivación del mercado interno...Una política económica así concebida se contrapone al pensamiento del liberalismo y neoliberalismo económico. Estas doctrinas han penetrado incluso en aquellas tendencias que expresan ideas reformistas y posibilistas". ${ }^{40}$

Una de las cuestiones consideradas fundamentales por esta organización para la reactivación del mercado interno es la modificación del sistema financiero, el cual había experimentado una fuerte transformación con la reforma de junio de 1977 impulsada por Martínez de Hoz. Por lo cual la demanda de derogación y modificación de la "ley" de entidades financieras de la dictadura está presente desde los orígenes mismos de APYME. Es conveniente recordar que la mayoría de sus dirigentes provenían del movimiento cooperativo de crédito, que habían tenido un papel activo en la oposición a la aplicación de estas reformas por parte de la dictadura, protestas que les permitieron la transformación de las pequeñas mutuales y casas de crédito en Bancos Cooperativos, lo que exigió al movimiento cooperativo la realización de modificaciones sustanciales para adaptarse al nuevo escenario.

La Declaración de Principios manifestaba que "la política financiera del Proceso no se ha modificado y sirve, en lo esencial, a estos mismos grupos. En tanto las pymes no cuentan con crédito adecuado, o cuando acceden a él, los intereses sobrepasan la rentabilidad".

En diferentes afirmaciones a medios de comunicación, sus dirigentes hacían hincapié sobre este aspecto, por ejemplo en una entrevista realizada en Rosario su presidente ex-

39 Diario Página 12, Buenos Aires, 6/8/1988. Archivo APYME Buenos Aires.

40 APYME, Reactivación del mercado interno. Democracia con contenido nacional y social, Acto Teatro Astral, Buenos Aires, 5/10/1988. 
ponía "es imprescindible para recuperar el mercado interno, modificar la ley de entidades financieras para poner el sistema financiero como servicio público para el desarrollo y el crecimiento del país". ${ }^{41}$

Es que la modificación instrumentada por Martínez de Hoz en la legislación permitía a los bancos fijar las tasas de interés perdiendo el Estado la capacidad para dirigir el crédito que había tenido en las décadas previas. Tal como afirma Basualdo ${ }^{42}$ esta reforma es un paso contundente para desarticular la estructura económica social de la industrialización por sustitución de importaciones, ya que pone fin tres rasgos que caracterizaban el sistema bancario hasta entonces, "la nacionalización de los depósitos por parte del Banco Central (BCRA), la vigencia de una tasa de interés controlada por esa autoridad monetaria y las escasas posibilidades de contraer obligaciones financieras con el exterior por parte del sector privado". De ahí al surgimiento de la deuda externa como una importante restricción para las políticas había sólo un paso.

En el documento elaborado por la organización en junio de 1988, citado un poco más arriba, se demanda "una ley de entidades financieras al servicio de la producción -y de todos los productores- en lugar de pedir tan sólo la baja de intereses nominales". ${ }^{43}$

Vemos entonces, cómo esta organización de empresarios exigía que se busquen los responsables de la deuda, de la inflación y que se desarmen los mecanismos que posibilitaban que estos sectores sean, una vez más, los beneficiados. Desde su concepción el crecimiento iba de la mano del apuntalamiento del mercado interno y de los sectores populares que lo conforman, incluyendo a los pequeños empresarios como parte integrante de dichos sectores populares.

\section{"Réquiem para el Plan Primavera"}

Sin reservas en el Banco Central en febrero de 1989, la devaluación no se hizo esperar ${ }^{44}$ como así tampoco la corrida contra el austral, la confirmación de que el Banco Mundial suspendería su ayuda a la Argentina actuó como una señal para iniciar esta corrida especulativa al dólar. ${ }^{45}$

41 Diario La Capital, Rosario, 9/3/1988.

42 BASUALDO, Eduardo, Estudios de historia económica, Siglo XXI, Buenos Aires, 2006, p. 128.

43 APYME, Las pymes enfrentan..., Op. Cit.

44 En febrero, el austral se devaluó un $12 \%$, se mantenían las tasas de interés altas y se liberaban los encajes a fin de aumentar la liquidez. El mercado cambiario seguía desdoblado, sólo que el dólar libre ya no tendría respaldo oficial puesto que el BCRA carecía de divisas para salir a vender. Si bien continuaba la política de control de precios a través de la Comisión de Seguimiento, el apoyo que había logrado el gobierno de las corporaciones empresarias se estaba esfumando.

45 GERCHUNOFF, Pablo y LLACH, Lucas, El ciclo de la ilusión y el desencanto, Emecé, Buenos 
La posesión de divisas seguía siendo el elemento de presión hacia el gobierno, los exportadores se negaban a liquidar las divisas al precio del dólar oficial, ejerciendo todavía más presión al alza de su cotización. Como el Banco Central se retiraría de la oferta, el precio del dólar iba a subir aún más, con lo cual las famosas "expectativas" se apuntalaban a sí mismas. Ya en marzo se evidenció el despegue; mientras el dólar oficial estaba en A $\$ 15,82$, el libre alcanzaba los A $\$ 47,9$ en el mismo mes (la disparada es clara cuando en junio el libre cotizaba casi 500 australes).

A pesar de que la situación prometía convertirse en caótica a nivel social, los que pudieron hacer uso de este circuito financiero se beneficiaron enormemente. Sin embargo, para el resto de la sociedad la incertidumbre era considerable, los plazos fijos ${ }^{46}$ se renovaban cada 7 días, con la especulación que esta inestabilidad conlleva, la creciente inflación era sumamente gravosa para los asalariados y los pequeños empresarios que no fijaban sus precios.

Con lo cual, para que se desate una crisis de extrema gravedad estaban dados todos los ingredientes. Al elevar las tasas de interés para promover el ingreso de divisas y así controlar la tasa de cambio y la inflación, la recesión en el mercado interno se acentuaba porque era más rentable realizar depósitos que inversiones productivas.

El año 1989 comenzaba además con una grave crisis energética, reiterados cortes de luz impedían programar la producción; el malestar se multiplicaba cuando se añadía el notable incremento que habían tenido las tarifas de energía.

Sin la intervención del gobierno en el mercado de cambios para controlar la fluctuación del dólar libre, éste se disparó y en febrero de 1989 se devaluó el austral. Con el salto del dólar los precios fueron detrás de él y se registró un aumento sostenido hasta que en mayojunio se produce la hiperinflación.

Sourrouille renuncia el 31 de marzo, es el propio candidato radical Angeloz quien solicita públicamente su alejamiento. Los grupos económicos nucleados en la UIA y la CAC, que habían acordado el Plan Primavera con el gobierno, también le retiraron su apoyo.

Una vez ya producida la devaluación, APYME hace público un volante "En la timba financiera las pymes siempre perdemos" en el que manifiesta que "los pequeños y medianos empresarios no han tenido participación en las consultas y decisiones sobre la política cambiaria y financiera. Son los operadores, los grupos concentrados, los grandes bancos, particularmente los extranjeros o los vinculados a ellos, los que han gravitado en las deter-

Aires, 1998.

46 En los primeros meses del año 1989 la tasa de interés para los plazos fijos a 7 días se duplicó de un mes para el otro, pasó de 4,2\% en enero a 9,8\% en febrero. Ver: SCHORR, Martín y ORTIZ, Ricardo, "Crisis del Estado y pujas interburguesas", en PUCCIARELLI, Alfredo (coordinador) Los años de Alfonsín..., Op. Cit. 
minaciones del equipo económico...también los grandes exportadores que siguen exigiendo una mayor devaluación del austral". ${ }^{47}$

El título del apartado está tomado de una solicitada publicada por APYME en marzo de 1989 reclamando una vez más el cambio de rumbo de la política económica ya que ésta había tenido resultados negativos para el sector como "un aumento de costos internos mayor recesión, mayor restricción al mercado interno... las pymes trabajan a niveles de subsistencia con altísimas tasas de interés incompatibles con el desarrollo de la pequeña y mediana empresa. Vemos en qué ha terminado el Plan Primavera que debía traer relativa estabilidad hasta las elecciones". 48

Pugliese es nombrado ministro de economía en reemplazo de Sourrouille y establece el $1^{\circ}$ de mayo de 1989 , la unificación y liberalización cambiaria tan reclamada por los sectores exportadores. Es esta medida la que ocasiona que el dólar tenga su mayor alza del año ${ }^{49}$ y que los precios siguieran ese aumento. Esta unificación va acompañada de un aumento en los combustibles del $25 \%$, las tarifas un $20 \%$, de un congelamiento de precios que nadie estaba dispuesto a acatar, más retenciones a las exportaciones tanto industriales como agropecuarias.

Si bien se esperaban las elecciones presidenciales, éstas ya estaban definidas y no a favor del radicalismo precisamente. El 14 de mayo, Menem gana con alrededor del 48\% mientras que Angeloz obtiene cerca del 32\%.

La especulación continuaba, el gobierno ya no tenía ninguna capacidad ni credibilidad para controlar la situación. Los precios se dispararon, desde agosto de 1988 (inicio del Plan Primavera) hasta julio de 1989 (asunción de Menem), la inflación fue en los precios minoristas un $3610,2 \%$ y en los mayoristas un $5061,9 \% .{ }^{50}$

La incertidumbre se había transformado en desesperación y se comenzaron a registrar saqueos a comercios en varias ciudades del interior, entre ellas Rosario. Con estado de sitio y varios muertos a cuesta, el radicalismo debe dejar el gobierno negociando la entrega anticipada. Sin que Menem la acepte oficialmente, Alfonsín renuncia el 15 de junio desde el 30 del mismo mes y el 8 de julio de 1989 asume la presidencia Carlos Menem.

Para lograr entregar el poder anticipadamente, los radicales se comprometen a no obstruir ninguna iniciativa del nuevo gobierno en el parlamento y brindar su apoyo a los proyectos que el ejecutivo considere. Es así como negocia la ley de Reforma del Estado ( $\left.\mathrm{N}^{\circ} 23.696\right)$, aprobada el 17 de agosto de 1989, y la ley de Emergencia Económica ( $\left.\mathrm{N}^{\circ} 23.697\right)$ el 1 de setiembre de 1989, que facultaban al Estado a privatizar las empresas estatales, suspenden

47 APYME, En la timba financiera las pymes siempre perdemos, Buenos Aires, 24/2/1989.

48 Solicitada Réquiem para el Plan Primavera, Buenos Aires, marzo de 1989. Archivo APYME Buenos Aires.

49 SCHORR Martín y ORTIZ Ricardo, "Crisis del Estado...", Op. Cit.

50 ACUÑA, Carlos, La burguesía industrial..., Op. Cit. 
los regímenes de promoción industrial, el "compre nacional" y las contrataciones en el Estado, autorizan la reforma de la carta orgánica del Banco Central que establecía que su función primordial sería preservar el valor de la moneda y no podría financiar ni al gobierno nacional ni a las provincias. Disposiciones que garantizan además igualdad de tratamiento al capital extranjero y al nacional, derogando normas previas en las que se debía autorizar su instalación, entre otras cuestiones.

Estas leyes constituyen dos de los pilares para las profundas transformaciones que se avecinaban en la próxima década.

\section{Algunas palabras finales}

La última parte del gobierno radical estuvo atravesada por la altísima inflación más la presión externa de los organismos internacionales e interna de los grupos concentrados. Frente a estas exigencias, el radicalismo intentaba mostrar 'señales' que denotaran la buena voluntad del gobierno, no pretendió buscar apoyos en los pequeños empresarios o en los asalariados, de todos modos el propio funcionamiento de su política vedaba esa posibilidad. Para poner en funcionamiento al Austral se apoyó principalmente en el respaldo conseguido internacionalmente con el gobierno de EEUU y en algunos grupos económicos locales. Para el Primavera realizó un pacto con la Unión Industrial Argentina y con la Cámara Argentina de Comercio.

La transformación de la estructura productiva operada en la dictadura, consolidó el poder de ciertos grupos económicos locales y extranjeros con capacidad de incidir en los precios del conjunto de la industria local y fue en estos sectores en los que el radicalismo se apoyó para sus planes, esperando reinversiones que no llegaron nunca y cumplimiento en los acuerdos de precios que se eludían constantemente. Estos sectores a través de una operación ideológica, adjudicaban al tipo de Estado y de sociedad constituida a través de la industrialización por sustitución de importaciones, la principal responsabilidad de la crisis.

El grado de condicionamiento que entonces constituía la deuda externa atentaba contra la soberanía del país, los planes económicos estaban destinados a cumplimentar esos "compromisos" y eran directamente discutidos en aquellos ámbitos. Eran ya corrientes las referencias a las reformas estructurales como la única salida. Reformas que en los años siguientes se realizaron en todo su esplendor.

El período ha sido analizado centrando la atención en las grandes corporaciones em-

presarias y los sindicatos, es por ello que a los fines de enriquecer la reconstrucción del mismo, indagamos en el posicionamiento que una organización de pequeños empresarios (APYME) sostuvo en esos años ya que no son tan frecuentes las referencias a estos actores.

A lo largo del trabajo nos detuvimos en estos años fundacionales en donde se recogen tradiciones del movimiento cooperativo de crédito, conformando y adquiriendo una nueva identidad como una organización con vida propia. Es allí y especialmente en repudio al Plan Primavera cuando se perfilan elementos por los cuales en los años posteriores APYME tendrá 
gran visibilidad como opositora al modelo neoliberal realizando acciones contenciosas en conjunto con otros sectores sociales.

APYME cuestionaba la estrategia del radicalismo de privilegiar intereses concentrados y las exigencias de los organismos financieros internacionales que implicaban un alto grado de dependencia. Política que a su entender mostraba continuidad con la de Martínez de Hoz, es que adjudicaban el momento de bifurcación precisamente a la dictadura militar de 1976, en especial con la reforma financiera que posibilitó la "financierización" posterior.

La crisis por la que atravesaba la pequeña empresa no encontraría soluciones con el rumbo elegido por el radicalismo; ya que con la política que el gobierno implementaba, beneficiaba a los mismos grupos concentrados que a su vez condicionaban tanto al gobierno como al resto de la sociedad, porque eran los formadores de precios y quienes poseían las divisas. A su juicio también, el desarrollo y la independencia económica sólo se alcanzarían con la ampliación del mercado interno, que compelía a considerar en conjunto la suerte de trabajadores y pequeños empresarios porque son parte sustancial del mismo. Por lo cual, exigían políticas de control de precios enfocadas en dichos formadores de precios que eran los responsables políticos de la situación.

Para ilustrar el grado en que se había depreciado la moneda nacional con las hiperinflaciones en los gobiernos de Alfonsín y también en el de Menem, mencionaremos que al comienzo del Plan Primavera (agosto de 1988) se podía comprar 1 dólar con 14 australes; cuando se sanciona la ley de Convertibilidad, casi 3 años después, se necesitaban 10.000 australes.

Semejante desvalorización de la moneda nacional y los aumentos de precios que siguieron a este exagerado incremento de la divisa norteamericana provocaron desastres sociales de gigantesca magnitud y condenaron a la mitad de la Argentina a la pobreza.

Y también sirvieron para disciplinar sectores díscolos y aún reacios a las tan alabadas 'reformas estructurales'; porque después de todo ¿podría ocurrir algo peor? Sorprendentemente, sí.

Recibido: $15 / 04 / 2012$

Aceptado: 08/07/2012 